\title{
TOWARDS AN ETHNOGRAPHIC THEORY OF THE NATURE/CULTURE DISTINCTION IN JURUNA COSMOLOGY*
}

\section{Tânia Stolze Lima}

In his celebrated comparison between studies of hysteria and totemism, Lévi-Strauss refers to a situation where the thoughts of the scientist account for more than those of the people studied - the latter for this reason becoming "more different than they are" (Lévi-Strauss, 1974, p. 5). This image comes to mind when I find myself faced with certain characterizations of indigenous Amazon cosmologies employing notions such as anthropocentrism or animism: these remind me directly of the totemic illusion - that is, the idea that it should be possible to deduce the identity between animality and humanity, nature and culture, from ethnographic materials.

Starting from the obvious fact that the extensive and intensive definitions of the terms nature and culture are historical and/orcultural products, I shall argue that the differences in the ways this distinction functions in various semiotic systems or "regimes" (see Deleuze and Guattari 1984 and 1988) is a more significant ethnographic fact than the diversity of

* Published originally in Revista Brasileira de Ciências Sociais, volume 14, n. 40, June 1999, pp. 43-52.

Translated by Frances Tornabene de Sousa and revised by David Rodgers and the author. contents it may assume in particular epochs and cultures. First I shall make some brief observations concerning this distinction in anthropology, before moving on to the Juruna ethnography. ${ }^{1}$

\section{Nature and culture according to ourselves}

In the process of taking these two terms as macro classes between which all things can be distributed, we place humans in both classes. And with this move, we submit the distinction to a concentric schema. Perhaps the best illustration of this method can be found in Lévi-Strauss (1967 and 1976). Nature includes (enables and in a certain sense determines) culture; the latter is both part of nature and one of its particular modalities of expression. Even for the anthropologist who, like Sahlins (1976), rejects the abstract reductionism of Lévi-Strauss and asserts that it is culture that determines nature, it seems impossible to escape a concentric reading of the distinction. Moreover, one finds in the work of Lévi-Strauss not only both ways of conceiving their relationship but also a synthesis of the two models, one which expresses the idea that nature must be determined by culture. 
It is also true that the distinction may be represented by a segmentary schema, since it may be transposed to the field of culture, thereby generating a dichotomy between "society" and "culture". In this instance, it is generally "society" that receives the values attributed to nature, while "culture" may become newly dichotomized as an opposition between "material culture" and "symbolism".

But this segmentarity should not conceal the fact that at each of its levels the terms still obey a concentric regime. For Durkheim or RadcliffeBrown, for example, "culture" is clearly enveloped and determined by "society", while for Sahlins, the inverse is true.

Expressing, therefore, a hierarchical reading of the distinction, anthropology shares with common sense the strange idea that nature is more real than culture, that nature is objective while culture is not. Moreover, it is on this basis that Lévi-Strauss formulates the curious paradox of the opposition of nature and culture. He begins by observing that its simplicity would fall apart if it were the work (as the anthropologists claim) of humanity as such, as then, he continues, "it would be neither a primitive fact, nor an objective aspect of the world's order" (LéviStrauss, 1967, p. xvii.). That is, if anthropology were correct in saying that humans distance themselves from nature, then the opposition would be strictly imaginary. The way out of this paradox is wellknown: Lévi-Strauss proposes the existence of a real continuity and a logical discontinuity between nature and culture, an outcome that then allows the opposition to be employed as an instrument of analysis.

If an anthropologist like Lévi-Strauss can choose to disbelieve in the opposition of nature and culture in the name of a "superior naturalism" (Sahlins, 1976), it may also be rejected in the name of a new culturalism, based on the principle of "natural relativism" (Latour, 1994).

In an attitude which at first seems to clash with current anthropological rhetoric, Bruno Latour (1994; Latour and Woolgar, 1997) maintains that if there is one rule to be respected in any ethnographic research into the science and cosmology of selfstyled "modern" societies, this rule is none other than to disbelieve in scientists and epistemology, and to break with the (self) definition of the modern world. In other words, it is above all necessary to break with the great nature/culture division.

Arguing that the distinctions such as Us and Them, Moderns and Pre-Moderns, Modernity and Tradition, produced by modern cosmology (of which anthropology would be part) derive from the transposition of this great division onto the whole of humanity, Latour asserts that this operation casts an asymmetric character on anthropology. I think that his alternative - a symmetric anthropology - depends primarily on thinking of the nature/culture distinction in a non-concentric and therefore a non-hierarchical fashion. ${ }^{2}$

What deserves stressing here is the radical transmutation this approach allows Latour to introduce into anthropology: the plurality of nature! In a gesture that evokes the figure of Boas, it is perhaps possible to say that following the pluralist revision of the notions of civilization and the history of humanity, we can now envisage the extension of this procedure to nature. The outcome is doubly significant: (a) nature is not natural but fabricated; (b) culture is not cultural but... real. Just as real as nature, at whatever level we happen to find ourselves.

Latour's argument, on the other hand, is pursued in such a way that taken in the light of Juruna ethnography, it appears to wrap itself in a paradox. By transforming the distinction into a true identifying trait of the (self-styled) moderns, Latour seems to suggest a portrait of Amerindians as peoples who would not separate nature and culture... thereby re-instating the same division of Us and Them condemned by the author himself at his outset.

His works are without a doubt of some interest to those who study Amazon cosmologies, and my impression is that nowadays there is a tendency to claim that "based on Latour" these cosmologies ignore the nature/culture distinction. I will try to show why I disagree with this tendency, and that more important than the question of the presence or absence of this distinction is the question of the diversity of the regimes through which it operates. 
The hypothesis underlying my analysis is that the great division comprises one specific regime for dealing with the nature/culture distinction. This regime can be provisionally characterized as follows: applying itself all at once to various levels of reality, the great division necessarily imposes the overlapping of these levels, overcoding, as Deleuze and Guattari would say, the distinctions generated at each level. In other words, the distinctions between Nature and Culture, Objectivity and Subjectivity, Truth and Error, Writing and Orality, Moderns and Pre-Moderns, Future and Past, and so on, are articulated in such a way that the moderns retain nature, objectivity, truth and even time itself, leaving the leftover terms for other societies.

What takes place in Juruna cosmology is very different. Distinctions such as River and Forest, Living and Dead, Humans and Animals, Consanguinity and Affinity, White-Lipped Peccary and Collared Peccary, do not overlap: the peccary is not a consanguine, nor are the dead of the forest.

\section{Nature and culture according to the Juruna}

Looking at the question from a distance, one can affirm that the notions of nature and culture have no counterparts in Juruna cosmology. Such an assertion is primarily based on two pieces of ethnographic evidence: humans do not belong to the class of animals, nor do they distinguish themselves precisely from the latter through the possession of culture, language and social life.

These last three functions are primarily related not to humans but - how to put this? - to the living beings that inhabit the different regions of the cosmos, some of whom are defined as having souls and others as being souls. For animals, spirits and humans, having a soul means having awareness of oneself and others, being able to think, being a subject. Whoever thinks or lives in effect behaves like humans: in this sense, animals have an awareness of their own humanity, act in accordance with this, and consider humans properly speaking to be their similars; in turn, the souls of the dead think of themselves as living people.
Here, culture denotes a universal function which is simultaneously defined as thought and sociality (and is, therefore, neither a domain isolated from an exterior reality, nor a distinctive function of humanity in opposition to animality). ${ }^{3}$ This fact is suggestive of a profoundly anthropocentric vision of the world and seems to correspond to what is conventionally called animism. From Tylor to Descola, the question of the applicability of the nature/culture distinction to so-called pre-modern systems has been put forward. The question is whether it is suitable for us to apply such labels to Amazon cosmologies: despite Descola's argument (1992), I think it is not.

Firstly, the question of culture is not only situated on the level of generality that I just outlined. There is another level, for which we may conveniently employ the term civilization, a level defined by the diversity of food regimes, numerous musical instruments and artifacts, categories of spirits and regions of the cosmos, and even the environmentitself wherein the lives of humans and animals unfold. And here a differential between wild and civilized is introduced: certain human societies have practices that are reminiscent of those of the jaguar.

It is true that on the first level the humans implied are the Juruna: peccaries and howler monkeys think and act as if they were Juruna. However, as far as the human genus is concerned, each social group possesses its own modes of action, and their subjective experience is not a simple replica of the action and subjectivity of the Juruna.

Secondly, what I learnt about the soul and civilization amounted to a very elementary lesson: (a) animals and the souls of the dead have different points of view to ours in respect to reality, and (b) the Juruna are not necessarily in agreement with what these other beings think of themselves and the Juruna.

I believe, then, that to fashion a general characterization of Juruna cosmology through the use of notions like anthropocentrism and animism is to lose sight of the essential: for the Juruna, the relation of identity between humanity and animality is primarily given as a condition for imagining their difference (Lima, 1996). 
In order to define the relations of similarity and difference (or identity and alterity) the Juruna employ a conceptual device formed by the terms nana and imama.

Between two cats, similarity exists; between a cat and a dog, difference. Between two parallel cousins, similarity exists; between two cross cousins, difference. Nana serves to distinguish the classificatory kin relation from the full relation, while imama serves to distinguish (within the kinship domain as a whole) consanguinity and the full affinity of the relation between cross cousins, marking the latter as a relation of alterity. In addition, when applied to the sociological domain, the two notions follow gradients: more similarity exists between two parallel first cousins than between second cousins; more alterity exists between non-kin than between cross cousins. To summarize then: (a) nana expresses the similarity between individuals of the same species and ima$m a$ the alterity between individuals of different species; (b) a parallel exists between the diversity of animals and the diversity of social relations.

That one and the same device allows the two types of diversity to be thought simultaneously is not surprising following the critique of totemism developed by Lévi-Strauss. In fact, the best evidence that Juruna ethnography provides in respect to the totemic method are two animal societies in which differences between kinship relations, combined with differences in social status, link people who belong to distinct species.

This homology between the differences of animals and of social relations implies not only that humans can (and should according to the message of certain myths) apprehend the political alterity between social groups through the model of animal diversity; animals can also apprehend their relation with others - those that are relatively close to their species - as a social relation of alterity. This is the case in vulture society: formed by king-vultures, red-headed vultures and yellowheaded vultures, the three species are similar in forming one and the same social group; but also different, since they are united through cross kin relations and by distinct social statuses - chiefshaman, warriors and patemal aunts respectively.
In a certain sense, this also occurs with animals such as the peccary or howler monkeys: imagining their difference with the Juruna as a case of political diversity, they show themselves disposed to take the Juruna as partners.

On the other hand, imama is an epithet signifying "wild" when linked to the jaguar or to an unknown human group; these are distinguished as "Other of a jaguar quality" and "Other of a human quality". However, linked to the name of a known person, the epithet indicates someone with whom the speaker has a highly elaborate and ritualized sociability, marked as a joyous relationship. ${ }^{4}$

In effect, alterity can assume two forms - a wild aspect (kill or die) and a civilized aspect. In a situation where their physical integrity is not threatened, the Juruna adopt a friendly and civilized conduct with a "wild Indian", just as (in symmetrical fashion) a shaman, in his dream life, would act when faced with a jaguar. It is said that when someone dreams of a jaguar (equivalent to a wild hunter in the shaman's dream life), the dream signifies that in waking life the person will be attacked by a wild Indian.

It is important to observe that if we focus on the imama relation a way that prevents ourselves from being able to observe the terms it links, we will be led to construct an artificial ethnographic product: alterity, and consequently sociality itself, will reveal itself to be contradictory and paradoxical. Perhaps a cosmology is relatively analogous to a phonological system, in the sense that allowing the terms to disappear represents losing reality itself to a false identity that no longer means anything. In the case of Juruna cosmology, it is also necessary to consider the status of the subject (whether human, or animal of a certain species, or soul of a particular category), as well as the level of reality (whether awake or dreaming, in this world or in the celestial, subterranean or aquatic worlds), for which (or in function of which) the relations in play gain reality.

In another work, I argued that the three basic categories of living beings in the Juruna cosmos (humans, animals and spirits) communicate with each other in such a way that each one can contain or can be contained in the other. This implies that 
humanity also characterizes beings that we designate as spirits, while divinity and animality also distinguish certain humans, and within (what we call) spirits, some are conceived as living in the form of souls, while others are as palpable as ourselves. In addition, all animals can transform themselves into humans. It appears to me that while we attempt to explain the totality of the universe all at once with the three orders of Man, Nature and Supernature, the Juruna proceed in another way. Utilizing analogous notions, their thinking appears to proceed in parts, producing an inventory of each case and distinguishing what is human, divine and natural in the class of humans, the class of animals and the class of spirits. Exemplifying this, the collared and white-lipped peccaries are animals, but not of the same kind, since the white-lipped peccary is also akin to the souls of the dead, which undoubtedly makes it closer to humans. The capuchin monkey is an animal, yet the night monkey is a phantom. In sum, each one of the three categories ordering the Juruna vision of the world comprises beings marked with values derived from the other two (Lima, 1995, pp. 59-60).

At times, it has appeared to me that the tripartition of nature, culture and supernature is not applicable to the Juruna materials without problems and, involuntarily, I have ended up producing a description that expresses a concentric and taxonomic anthropological theory of the nature/ culture relation, rather than the ethnographic theory that I am pursuing here. I now think it is possible to argue that:

(1) given that the class of humans comprises humans, animals and spirits, and that this is repeated in the other two classes, these categories do not represent classes in the strict and usual sense of the term;

(2) a more adequate analytical procedure would be to examine whether we are not faced with three relations of opposition: human/nonhuman, animal/non-animal, spirit/non-spirit; in this way, we would reach an ethnographic level at which, instead of (the expected but non-existent) classes defined by their reciprocal opposition, we would have access to the regime which prevails in the cosmological system as a whole;
(3) a triad of oppositions can be applied to each entity ortype of being, in such a way that each entity consists of "a cluster of oppositions"; for example, a collared peccary may not be a peccary or an animal, but a spirit;

(4) this means that, from an ethnographic point of view, the differential between animal species should not be eliminated due to its common belonging to the class of animals;

(5) the same requirement is imposed on humanity; exemplifying this, humanity divides into the Juruna, peoples of the forest and whites: the Juruna are simply humans, the second present values linked to animals (drinking only water, and eating almost raw meat), while the last, through their technological power and spatial journeys, present values linked to the divine shaman who created humanity;

(6) as in the case of the human genus, there are "genuses" formed by animal species that are taken to be proximate; for example: the monkeys, which comprise (among others) four important species: (a) the capuchin monkey and the spider monkey are animals in a double sense: they are named as such and are considered prey; (b) the night monkey, which is not an animal but a phantom; and (c) the howler monkey, which is an animal in the proper sense of the term, but only the ancient Juruna - they say - treated it as prey (currently, people consider that they "appear like phantoms" and feel no desire to eat them; they narrate a myth about the conjugal life of the howler monkeys in which the husband provokes the wife's jealously by threatening to go to a Juruna beer festival);

(7) it is notable, however, that the three oppositions are applied in order to draw a differential relation between the terms of a same genus;

(8) on the other hand, the relations between the terms (the Juruna and the peccaries, the vultures, and the dead, etc.) present a considerable potential asymmetry: if a human point of view has a greater chance of prevailing over an animal point of view (in hunting, for example), this chance diminishes significantly when confronted with the spirit's point of view (in the festival of the dead, for example); 
(9) asymmetry should be understood here as the capacity of a subject (human, animal or spirit) to impose its point of view on another;

(10) since it follows that the Juruna believe an animal point of view can, in theory, prevail over their own (for example, a hunter becoming first an enemy and then a captive of the prey), then a spirit point of view can also show itself to be insufficiently potent to dominate a human;

(11) or put otherwise, asymmetry is a reversible relation, and this means that it cannot be considered to be determined a priori; at least in principle, the domination of one over another is only determined a posteriori;

(12) in addition, the triple opposition allows the distinguishing of common phenomena from singular phenomena; this corresponds to a differential between ordinary human life dominated by the human point of view, and the unusual - that is, a situation in which the animal or spirit point of view transforms human reality for humans themselves;

(13) this makes evident the fundamental presence of a fourth opposition, namely, the distinction I/another, or put better, Other/non-Other;

(14) finally, the difference between points of view has nothing to do with the theory of cultural relativism, as it is not based on any of the characteristic notions of Anthropology, namely: partiality, arbitrariness, equivalence, incommensurability and antinomy between object and subject, that is, nature and culture (Lima, 1995);

(15) what the Juruna theory emphasizes is the struggle between points of view and that reality is what the point of view affirms.

I believe, therefore, that the point of view of the animals represents not so much the inapplicability of a differential between nature and culture, but rather the inexistence of the overlapping, which, according to ourselves, may be conceived between the dichotomies of nature/culture and animal/ human. I emphasize again that these terms do not designate impermeable domains of reality, but a differential relation which is better translated by the qualifiers wild and civilized. ${ }^{5}$

In order to describe this cosmological regime, I shall base my argument on Deleuze and Guattari
(1988). According to the authors, there are two possible modes of dealing with a variable: either making it operate as a constant, or putting it into a state of continuous variation. I think the latter is a more appropriate way to characterize a cosmology in which the significant difference between humans and white-lipped peccaries, for example, is not the same as that between humans and the collared peccary, the jaguar, or the howler monkey. And this entails certain consequences for analysis. What firstly stands out is that differential relations cannot be analyzed in terms of concentric, hierarchical and atemporal schemas; secondly, it avoids projecting onto the Juruna materials a principle which is effective only in our own cosmology, namely, the idea that the difference or distance between humans and animals is a constant.

In a world in which differential relations are placed in a state of continuous variation, a man, under certain conditions, can become a peccary, but in such a way that this becoming peccary amounts to a process which never reaches its end; even in a mythic space where the continuous state of variation encounters greater chances of realization, a differential relation persists. It is also a world in which a collared peccary that invades the village may no longer be simply an animal.

The fundamental question of Juruna ethnography is less animism than perspectivism: the notion of soul represents only a point of support for a specific theory of the relationship between points of view which are at one and the same time analogous and locally determined as asymmetric. And this theory expresses less a notion of a general humanity of all beings than a certain dualism. This I shall now address.

This dualism translates as the difference between Life and Dream, between the reality of the subject and the reality of its soul. As the dream is marked with values linked to death and alterity, the reality of the soul is generally determined by an alien point of view (the one of which one dreams). Understanding this distinction as Nature and Supernature is not to distort the ethnographic materials, but these are here essentially relational metacategories, variable according to the point of view, that is, according to the reality lived as such by a subject. 
What does this mean? Imagine that in our own cosmology the dead imagined us as souls and themselves as living! In the Juruna cosmological economy it is thus: the dead apply to themselves the distinction of body and soul and conceive of the living as being purely soul... The relationship with the animals is no different, but the fact can appear extremely complex, probably due to the fact that we do not confer to souls the same degree of reality as we do to animals.

The relation with the animal is such that, being the case that it sees itself as human (and sees the Juruna as human as well), its animal side ignored by itself - represents the supernatural aspect of its existence. In this sense, the sensible reality of humans is coextensive with the animal's supernatural aspect and vice-versa. Or, put differently, what for the Juruna comprises the function of the animal's body has for the animal the function of its soul. ${ }^{6}$

Imagine now that the Cariocas (people bom in Rio de Janeiro) defined themselves as such in opposition to Paulistas (people born in São Paulo), who in turn defined themselves as Cariocas! This may seem funny, but it expresses an excessively recurrent mechanism in our experience, and we are only notimmediately aware of this because we treat the categories of alterity as substantives. The model par excellence of these relational categories are the personal pronouns of the first and second persons (Viveiros de Castro, 1996), and the small experiment of deploying the terms "Carioca" and "Paulis$t a$ " as "collective pronouns" analogous to "I" and "you" swiftly reminds us of the strange ease with which humans fall into alienating processes of reification. Among ourselves, for several centuries even temporal categories have undergone an incessant process of substantiation, and now it is modernity itself which we attempt to freeze in the pastand supercede in the present. ${ }^{7}$

The relativity of the cosmological and/or sociological categories define perspectivism (Lima, 1996; Viveiros de Castro, 1996). It may be objected that this label is merely a mannerism, and that the principle before which we find ourselves is merely a contextualism; at most, an example of segmentarity or "structural relativity" (Dumont, 1975). Butmy argument is precisely that we are dealing not so much a global system of segmentarity (in such a way that at some moment the distinction between Cariocas and Paulistas would dissolve to make way for the distinction Brazilians versus other national identities), but with a scheme for which the point of view of the definition of categories of alterity pertains to the terms themselves, and not to a term situated within a superior point of view. For it is evident that, in our sociocosmological system, the distinction Cariocas and Paulistas is permitted by a point of view which is dislocated in relation to the terms and which is superior to them: the point of view of the whole. The label perspectivism is useful and, I believe, necessary in order to translate the absence of the point of view of the whole, ${ }^{8}$ and therefore hierarchy defined a priori.

Another objection would be the following. If we consider that the most adequate anthropological approach would be that which is capable of allowing the lived world (Gow , 1998) produced by the groups that we study to have the last word about the play of symmetries in ethnographic texts, it could be objected that perspectivism conceals a "non-perspectival residue", meaning by this the fact that, for the Juruna, the tucunare (peacock bass) is simply the tucunaré! For the Piro, a peccary is just a peccary! The objection is valid but is not insurmountable, since this problem is not alien to the Juruna, who confer on it precisely a perspectivist treatment, as I will now show. ${ }^{9}$

Taken in the strict sense, the human being, alive and alert, presents an irreducibility that I cannot avoid stressing: its inimitable "wisdom". The antonym of wisdom translates the most varied concepts: "incest, bestiality, adultery, sexual and verbal incontinence, intrepidity, mental stupidity and the exchange of words with animals", all related to incredulity, and which directly or metaphorically evoke a tapir quality or affect, if not the actual transformation of the person into a tapir.

Human wisdom consists of that which we ourselves call recursivity: the living know that the dead consider the tucunare to be a corpse, but the dead do not know that this is what they know, nor that the living consider the tucunaré as tucunaré. Their relative insensateness, or that is, this inability 
to put themselves in perspective also characterizes our own dream existence and the condition of animals. The peccary knows itself to be human, knows that a Juruna is a similar, butdoes not know that it is a peccary for the Juruna.

This is the type of moral relation which the Juruna entertain with animals. A bit like Rimbaud put it: "Too bad for the wood if it finds out it's violin!"

\section{Conclusions}

To conclude, it is necessary to highlight some points:

(1) In the study of indigenous cosmologies, it is impossible to situate the question of the nature/culture and human/animal distinction on a level of generality such that the internal diversity of each of these terms loses its relevance. I have tried to show that we can understand this phenomenon as a manifestation of a positive property of Juruna cosmology, namely, perspectivism, which, formulated in negative terms, consists in the absence of a point of view of the whole, that kind of panoptic point of view which generates the illusions of objectivity and absoluteness. The classificatory operations that we can observe do not suppose a distancing of the subjectin relation to the constituted world, but, on the contrary, its interaction with what is being classified, an interaction that is always changing and (as Lévi-Strauss showed) always attentive to sensible qualities, and also (as Lévy-Bruhl showed) to the unusual.

(2) The hierarchical relation between nature and culture characteristic of our way of thinking is not opposed to the absence of hierarchy in Juruna cosmology. What is observable in the latter is hierarchy operating in a regime that impedes the $a$ priori codification of relations, imposing itself only a posteriori, the cosmological dynamic depending much more on a principle of variation of entities and of their reciprocal relations, rather than on a non-temporal system where all the entities would occupy a predefined position.

(3) Mauss showed that "giving" produces an asymmetry (an obligation or subordination) and that, in the gift regime, the only way to liberate oneself from this is to provide a "return". As gift systems involve relatively long-term partnerships, this means that retribution cancels asymmetry only at the price of producing another. To give-andreturn can be interpreted as a symmetry between two asymmetric relations. On the other hand, Deleuze and Guattari characterize the gift as a regime of finite debt, while Bourdieu (1996) shows that, in the capitalist world, the gift presents a distinct form, creating enduring asymmetries, that is, making it impossible to return in kind! In the terms of Deleuze and Guattari, this is a regime where the debt reveals itself to be infinite. I hope to have been able to show that hierarchy can also be finite.

(4) I propose to characterize as perspectivist the contra-hierarchical systems in which, on one hand, hierarchy is only able to operate in a regime of finitude and, on the other hand, the part, as Henry James (1994) suggests, comprises all of reality. For, in truth, the Juruna notion of point of view diverges immensely from our notion, since it is not limited by any character of partiality (that is, falsity). It is therefore necessary to define more precisely what is meant by an absence of any point of view of the whole in contra-hierarchical regimes. It remains Deleuze and Guattari (1984, p. 42) who offer the best possibility of understanding the processes in question here: "We believe only in totalities that are peripheral". A type of whole exists that does not totalize nor unify the parts, a whole whose functioning is very different from that of a transcendent totality, since it behaves as "a part alongside other parts", "though it has an effect on these other parts simply because it establishes aberrant paths of communication between noncommunicating vessels, transverse unities between elements that retain all their differences within their own particular boundaries" (idem, p. 43).

(5) We should not invoke relations of privative opposition in the comparative study of cosmologies. Even the difference of regimes that I have argued here can not be taken as an opposition between the Juruna and ourselves. Who can assure that the relation with a pet is a constant, independently of it being a dog, cat or a turtle? Who can assure that, for the cowboy, the signifi- 
cant difference between man and cattle is the same that exists between man and horse?The distinction proposed by Deleuze and Guattari is not intended to be applied to two kinds of cosmologies, but to two uses of a single cosmology, one use "major" and another "minor". ${ }^{10}$ In any case, the analysis provided here should be taken as the preparative stage for a finer analysis, one capable of breaking the illusory unity that consists in speaking of "the" Juruna cosmology, in favour of the apprehension of more differentiated semiotic regimes.

\section{NOTES}

1 The Juruna are a small Tupi people who live in the upper Xingu. Canoeists, farmers and hunters, they inhabited the islands of the middle Xingu until the end of the XIX century. My fieldwork with this group took place between 1984 and 1990 and was supported by funding from the Ford Foundation and Financiadora de Estudos e Projetos (Finep).

2 "When I say there is no inside/outside distinction, I mean that we should not believe in the existence of inside and outside. We should sit exactly at the place where the inside and the outside of the network are defined. So the point is exactly the same: we have to see inside-and-outside as an active category, created by the actors themselves, and it has to be studied as such." (Latour and Crawford, 1993).

3 Thought and language mutually imply one another: the first is silent language, without a voice. This is recorded in the space of cosmogonic myths, where the mythic inscription of the difference between humans and animals stands out, (a) the humans transformed into animals already bore prefigurations of their specific animality, and (b) what the myth extracts from the animals is not exactly the language but the possibility of their communication with humans in the waking world.

4 This double meaning of the term imama is expressed in the Portuguese of the Juruna through the use of two terms: brabo and Outro (wild and Other).

5 I think in fact, that the distinction between wild and civilized is not strange to the Juruna, nor is it lacking in importance. But it has nothing to do with the evolutionist anthropological distinction: the wild is not primitive and civilization consists above all in the knowledge and preservation of cultural practices given since the origin of present day humanity.

6 While it is true that in Juruna cosmology the expression of this perspectivism reveals itself to be fairly abstract, other Amazonian systems express it in a relatively more concrete form: according to the Makuna or the Wari (Århem, 1996; Vilaça, 1996), the differential between humans, represented as predators, and animals, represented as prey, is directly expressed by means of two relational categories. In this sense, it could be said that the humans are the animals of the animals! An equation of the same type is true, in part, for the Juruna dead, but not though for Juruna animals.

7 For a critique of contemporary attempts to essentialize modernity, see the twin texts of Foucault (1994).

8 For an examination of this question in a different ethnographic context, see Strathern (1992). My distinction between contextualism (parts integrated into a larger whole, that in its turn is part of a larger whole and so on in succession) and perspectivism does not mean, obviously, that the Juruna are incapable of thinking in terms of context. It also does not mean that perspectivism has been ignored in fields other than the plastic arts: the work of Henry James (1994) is full of this. Consider also the example of Nietzsche.

9 My thanks to Peter Gow for criticisms which allowed me to develop this point.

10 "Majority implies a constant, of expression or content, serving as a standard measure by which to evaluate it. Let us suppose that the constant or standard is the average adult-white-heterosexual-European-male speaking a standard language (Joyce's or Ezra Pound's Ulysses). [...] For the majority, insofar as it is included in the abstract standard, is never anybody, it is always Nobody - Ulysses - whereas the minority is the becoming of everybody, one's potential becoming to the extent that one deviates from the model. There is a majoritarian 'fact', but it is the analytic fact of Nobody, as opposed to the becoming-minoritarian of everybody." (Deleuze and Guattari, 1988, p. 105).

\section{REFERENCES}

ÅRHEM, Kaj. (1996), "The Cosmic Food Web: HumanNature Relatedness in the NorthwestAmazon", in P. Descola and G. Pálsson (eds.), Nature and Society: Anthropological Perspectives, London, Routledge.

BOURDIEU, Pierre. (1996), "Marginália. Algumas Notas Adicionais sobre o Dom". Mana, 2(2): 7-20.

DELEUZE, Gilles and GUATTARI, Félix. (1984), AntiOedipus. Capitalism and Schizophrenia. London, The Athlone Press.

. (1988), A Thousand Plateaus. Capitalism and Schizophrenia. London, The Athlone Press.

DESCOLA, Philippe. (1992), "Societies of Nature and the Nature of Society", in A. Kuper (ed.), Conceptualizing Society, London/New York, Routledge, pp. 107-126. 
DUMONT, Louis. (1975), Introducción a Dos Teorías de la Antropología Social. Barcelona, Anagrama.

FOUCAULT, Michel. (1994a), “Qu'est-ce que les Lumières?' (1984), in M. Foucault, Dits et écrits, vol. 4, Paris, Gallimard, pp. 562-578.

. (1994b), “Qu'est-ce que les Lumières?' (1983), in M. Foucault, Dits et écrits, vol. 4, Paris, Gallimard, pp. 679-688.

GOW, Peter. (1998), "A Man who Was Tired of Living". How an Amazonian world changes in time. London, London School of Economics, mimeo.

JAMES, Henry. (1994), Pelos Olhos de Maisie. São Paulo, Campanhia das Letras.

LATOUR, Bruno. (1994), Jamais Fomos Modernos: Ensaio de Antropologia Simétrica. Rio de Janeiro, Editora 34.

LATOUR, Bruno and CRAWFORD, T. Hugh. (1993), An Interview with Bruno Latour. Virginia Military Institute. Internet.

LATOUR, Bruno and WOOLGAR, S. (1997), A Vida de Laboratório: a Produção dos Fatos Científicos. Rio de Janeiro, Relume Dumará.

LÉVI-STRAUSS, Claude. (1967), Les Structures Élémentaires de la Parenté. Paris, Mouton. PUE.

. (1974), Le Totémisme Aujourd'bui. Paris,

(1976), O Pensamento Selvagem. São Paulo, Companhia Editora Naiconal.

LIMA, Tânia Stolze. (1995), A Parte do Cauim. Etnografia Juruna. Rio de Janeiro, doctoral thesis, PPGAS/Museu Nacional/UFRJ.

. (1996), “O Dois e seu Múltiplo: Reflexões sobre o Perspectivismo em uma Cosmologia Tupi". Mana, 2(2): 21-47.

SAHLINS, Marshall. (1976), Cultura e Razão Prática. Rio de Janeiro, Zahar.

STRATHERN, Marilyn. (1992), "Parts and Wholes: Refiguring Relationships in a Post-Plural World", in A. Kuper (ed.), Conceptualizing Society, London/New York, Routledge, pp. 74104.

VILAÇA, Aparecida. (1996), Quem Somos Nós: Questões da Transformação no Encontro dos Wari' com os Brancos. Rio de Janeiro, doctoral thesis, PPGAS/Museu Nacional/UFRJ.
VIVEIROS DE CASTRO, Eduardo. (1996), “Os Pronomes Cosmológicos e o Perspectivismo Am eníndio". Mana, 2(2): 115-144. 